\title{
Da antipolítica ao acontecimento: 0 anarquismo dos corpos acontecimentais
}

\section{From anti-politics to the event: the anarchism of the evental bodies}

José Luiz Aidar Prado

Resumo: $O$ acontecimento que rompe com a ordem estabelecida, com os estados de coisas com representações estáveis, só pode surgir a partir de uma visão pós-fundacional de política em que esta não é gestão condominial dos seres a partir dos biopoderes midiatizados, mas surgimento da voz dos que não têm voz, do povo, a partir das demandas diferenciais que, de início, não dialogavam. A teoria materialista da comunicação é aqui pensada a partir de um antagonismo de base, de uma negatividade da ordem pulsional que circula em um campo tensivo a partir do qual as partes buscam performativamente, na luta pelo reconhecimento (Honneth) e pela visibilidade, a emergência de acontecimentos disruptivos (Badiou). Como os discursos pela democracia radical podem, nessa perspectiva, ser constituídos fora dos arautos corrompidos do sistema tradicional? Como, no momento do acontecimento, emergem corpos anarquistas dispostos a mergulhar no processo de verdade que aí se inicia? Em termos de uma lógica dos afetos ou das paixões, o caminho da política se faz do medo para a alegria, da retenção para a libertação/emancipação. Nesta direção é que pensaremos a comunicação entendida como campo tensivo de emergência da política performativa acontecimental.

Palavras-chave: tensividade; acontecimento; política; afetos.

Abstract: The event, that breaks with the established order, within the states of things with stable representations, can only arise from a post-foundational view of politics, which is not a condominium management of beings from the perspective 
of mediatizated biopowers, but the emergence of a voice for the voiceless, of the people from the differential demands that at first did not dialogue. The materialist theory of communication presented here emerges from a basic antagonism, a negativity of the instinctual order that circulates in a tensive field from which the parts search in a performative way, while struggling for recognition (Honneth) and visibility, the emergence of disruptive events (Badiou). How can discourses on radical democracy be constituted in this perspective outside the corrupt heralds of the traditional system? How at the moment of the event do anarchist bodies emerge, ready to dive into the process of truth that begins there? In terms of a logic of affections or passions, the path of politics is made from fear to joy, from retention to liberation/emancipation. It is in this direction that we will think of communication as the tensive field of emergency for evental performative policy.

Keywords: tensivity; event; policy; affections. 
Temos, nos últimos textos (PRADO, 2013, 2015, 2016a, 2016b, 2016c; PRADO; PRATES, 2017), aprofundado uma perspectiva teórica comunicacional e semiótica para estudo de movimentos políticos que cruza a teoria discursiva, a teoria do acontecimento e a semiótica tensiva. No presente texto, abordaremos a parte teórica comunicacional para examinar posteriormente práticas concretas.

Ao traçarmos a genealogia do neoliberalismo, como fez Foucault (2008) e como fazem Dardot e Laval (2016), é preciso examinar discursivamente os enunciados que deram força à figura do homem empreendedor, esvaziando progressivamente a figura do cidadão "investido de uma responsabilidade coletiva” (DARDOT; LAVAL, 2016, p. 381). Assim, no discurso neoliberal,

A referência da ação pública não é mais o sujeito de direitos, mas um ator autoempreendedor que faz os mais variados contratos privados com outros atores autoempreendedores. Dessa forma, os modos de transação negociados caso a caso para "resolver os problemas" tendem a substituir as regras de direito público e os processos de decisão política legitimados pelo sufrágio universal. Longe de ser "neutra", a reforma gerencial da ação pública atenta diretamente contra a lógica democrática da cidadania social; reforçando as desigualdades sociais na distribuição dos auxílios e no acesso aos recursos em matéria de emprego, saúde e educação, ela reforça as lógicas sociais de exclusão que fabricam um número crescente de "subcidadãos" e "não cidadãos" (DARDOT; LAVAL, 2016, p. 381).

Nesse contexto neoliberal, a psicologia positiva euforiza, por um lado, o indivíduo alfa, construído como sujeito superpower dos "dínamos humanos operando em prol do próprio bem-estar e da ordem socioeconômica", na expressão de Freire Filho (2010, p. 77), e, por outro, disforiza os indivíduos fracos, os que culpam os demais por seus erros e frustrações, os que se sentem vítimas e não se adaptam ao mundo. Ela se adapta bem ao modo de funcionamento neoliberal, que conforma a ação pública "aos critérios de rentabilidade e produtividade" (DARDOT; LAVAL, 2016, p. 379), além de promover a 
[...] depreciação simbólica da lei como ato próprio do legislativo, fortalecimento do Executivo, [...] tendência dos poderes de polícia a isentar-se de todo controle judicial, promoção do cidadão-consumidor encarregado de arbitrar entre "ofertas políticas" concorrentes [...] (DARDOT; LAVAL, 2016, p. 379-380).

No lugar de princípios simbólicos que ancoravam a cidadania, está agora em operação a gestão condominial da sociedade.

O enfrentamento do neoliberalismo, porém, não pode ser feito como outrora, a partir de uma crítica da ideologia. Se a ideologia era então entendida como falsa consciência, hoje, em tempos de cinismo (cf. SAFATLE, 2008), não é mais possível pensar em raspar uma camada de significação dos discursos para apontá-los como falsos ou inverossímeis. À pergunta "o que significa oferecer uma crítica", Butler recorre a Foucault para construir a resposta: a crítica não deve se dirigir em bloco ao mundo, mas a práticas, discursos, epistemes e instituições, e "perde seu caráter no momento em que é abstraída de sua operação e feita para se sustentar sozinha como uma prática puramente generalizável” (BUTLER, 2004, p. 304). A crítica é como uma bússola com um led na ponta, colada em práticas concretas, em disputas e conflitos no meio do mundo; ela visa permitir que caminhemos entre os antagonismos, no escuro da mata, iluminando a cada passo os contextos de interação e conflito. Ela não ilumina de cima a arena da luta, mas caminha conosco. Ela não cartografa senão alguns centímetros adiante e vai praticamente materializando a rota, anunciando-a na medida em que o corpo desequilibra para dar o próximo passo. A crítica está situada a partir do corpo, embora se construa a partir de processos de verdades acontecimentais.

Entretanto, a metáfora da lanterna "linguajeira" não dá conta de figurativizar com precisão a crítica, pois há um jogo entre determinação e indeterminação nessa caminhada antagonista que exige que caminhemos muitas vezes no escuro e nos orientemos em e a partir de situações de indeterminação; o actante está no meio desse jogo, mas não há um marco de verdades eternas para distinguir sombras verdadeiras de falsas. A comunicação não é atividade parlamentar de consensos. 
A argumentação se dá a cada passo e a verdade se ancora nos acontecimentos e nos sujeitos que a eles se filiam. Contra essas verdades se colocam os sujeitos de discursos ligados aos dispositivos hegemônicos.

Se o mundo neoliberal localiza a fonte do sofrimento na falta de experiências produtivas de determinação (o sujeito como autoempreendimento de si), apostaremos nas experiências de não identidade. Uma teoria do reconhecimento nesta via deveria tentar incorporar as experiências de indeterminação ou, como diria Viveiros de Castro (2002), o encontro ameríndio contingente na mata. A palavra-chave aqui é, conforme Dunker (2015, p. 299), expansão da indeterminação.

Dessa forma, como afirmava Foucault (in BUTLER, 2004), a crítica não deve ser construída como um julgamento, um juízo geral. Para fazer a crítica como forma de práxis, diz Butler, é preciso apreender "os modos pelos quais as próprias categorias são instituídas”, ou seja, como o campo do conhecimento é construído e como "aquilo que ele suprime retorna como sua própria oclusão constitutiva” (BUTLER, 2004, p. 304, tradução minha). Como está construído o campo do conhecimento em que estamos operando, lutando, combatendo outros discursos? Como funciona nossa inserção ativa no meio dos discursos "em termos de suas habilidades de alcançar objetivos” (BUTLER; SALIH, 2004, p. 304)?

A linguagem em Butler é pensada de modo performativo, em que dizer, pensar e inscrever significa alterar regras, convencer, mudar campos epistêmicos, formas de gestão e biopoderes. Vivemos uma época em que os poderes estão orientados para gerenciar e controlar a vida, as populações. Não se trata de construir éticas normativas, mas de sustentar a crítica na direção da diminuição da subjugação, da subordinação, de atuar quando os modos de existência concretos se veem em risco. Essa atuação é política e não gestão condominial, que Rancière (1996) chama de polícia. Nessa perspectiva, a principal tarefa não é avaliar se seus objetos são bons ou ruins, valorizados ou não, mas "ressaltar a própria estrutura de avaliação" (BUTLER, 2004). Butler pergunta: "qual é a relação de nosso conhecimento ao poder, de modo que nossas certezas epistemológicas apoiam um modo de estruturar o mundo que suprime 
(foraclui) possibilidades alternativas de ordenação"? (BUTLER, 2004, p. 307).

Eu gostaria de ligar essa ideia de crítica e de dessubjugação à perspectiva badiouana. Badiou começa seu Lógicas dos mundos diferenciando o materialismo democrático da dialética materialista. Nossa crença atual mais espontânea é a seguinte: "não há mais que corpos e linguagens". É a crença espontânea do materialismo democrático ou pós-moderno. Nele, "o corpo é a única instância concreta dos indivíduos produtivos que aspiram ao gozo. O homem, no regime da 'potência da vida' é um animal convencido de que a lei do corpo apodera-se do segredo de sua esperança" (BADIOU, 2008, p. 18). Esse materialismo é um "biomaterialismo" que amplia a animalidade, pois os direitos do homem são os direitos do vivente; é um materialismo democrático, pois "o consenso contemporâneo, ao reconhecer a pluralidade das linguagens, supõe sua igualdade jurídica" (BADIOU, 2008, p. 18). Essa é a lógica multicultural do capitalismo globalizado, herdeira do pós-modernismo. Contra essa posição, Badiou propõe uma "dialética materialista” em que um terceiro termo surge para complementar a realidade dos corpos e das linguagens. Assim ficaria o enunciado da dialética materialista: "não há mais que corpos e linguagens, senão que há verdades". O haver verdades faz objeção ao enunciado do materialismo democrático: verdades não são corpos ou linguagens, mas "corpos incorporais, linguagens desprovidas de sentido, infinitos genéricos, suplementos incondicionados" (BADIOU, 2008, p. 20). Elas permanecem suspensas "entre o vazio e o acontecimento puro" (BADIOU, 2008, p. 20). O "senão que" indica que não se trata de adição das verdades aos corpos e linguagens nem de síntese dialética. "As verdades existem como exceção ao que há" (BADIOU, 2008, p. 21). Verdades não são somente correspondências adequadas entre objeto/estado de coisas e enunciados. Elas surgem como processos que alteram os estados de coisas a partir de acontecimentos.

Como se inicia um processo de verdade? Ele começa com a emergência de um ato (dito acontecimento) que rompe o estado de coisas, reembaralha o modo pelo qual é organizado o conjunto de elementos 
que caracterizam um estado de representação, ou seja, os quadros da ordem e da separação. O estado liberal coloca lei e ordem para proteger poder e riqueza. Dos sujeitos o sistema neoliberal espera o crescimento autoempreendedor, em que cada qual se prepara para aumentar seu capital de eu, agregando predicados e atributos. Nessa perspectiva, diz Badiou, a lei é a prescrição de uma ordem razoável para essa situação, para essa forma de conjuntação, de montagem de elementos em conjuntos. Alguns conjuntos são considerados existentes, visíveis, outros não. A estes últimos o sistema envia gás de pimenta, antidepressivos, prisão ou a bruma da invisibilidade. Para os integrantes que não são da "elite", o mundo não é líquido, mas bem sólido. As partes aceitas e cabíveis nos condomínios recebem o título de autoempreendedoras e as demais permanecem sem nome e sem lugar. A lei é, portanto, decisão sobre a existência, o que dá um caráter ontológico, para além do jurídico, para a lei de ordenamento desse estado de coisas (BADIOU, 2012, p. 67).

\section{Em busca do reconhecimento}

As lutas principais contra o capitalismo foram de redistribuição econômica até os anos 1970, quando a oposição enfrentada era de classe: de um lado a força de trabalho, de outro o capital. Mas, desde então, o proletariado deixou de ser o único sujeito universal que outrora unificava "a multiplicidade de manifestações sociais visando à emancipação política" (SAFATLE, 2015, p. 325). A partir dos anos 1960 e 1970, emergiram os "novos movimentos sociais", com as lutas feministas, gays, étnicas, pós-nacionais etc. Com isso, os enfrentamentos se deslocaram de uma política de classes para uma política das identidades.

Nos anos 1990, a teoria social, na pegada desses ditos "novos" movimentos, começou a reinventar a teoria das multiplicidades segundo novas bases. Isso não ocorreu somente devido à natureza das demandas, mas a partir, como nos diz Safatle (2015), leitor de Boltanski e Chiapelo (2009), das mudanças no ethos do capitalismo no pós-1968. Com isso, cai a centralidade do conceito de luta de classes e se eleva a grita pelo 
reconhecimento "como dispositivo político central" (SAFATLE, 2015, p. 326).

Alguns autores, como Axel Honneth (2003), afirmam que toda luta deve ser pensada como luta de reconhecimento. Nancy Fraser não concorda com isso e propõe pensarmos as injustiças como de redistribuição econômica e de reconhecimento cultural (FRASER; HONNETH, 2006).

Minha tese geral é que, na atualidade, a justiça exige tanto a redistribuição como o reconhecimento. Em separado nenhum dos dois é suficiente. Contudo, tão logo abraçamos essa tese, a questão de como se combinam ambos os aspectos cobra uma importância máxima. Mantenho que há de integrar em um único marco global os aspectos emancipadores das duas problemáticas. Do ponto de vista teórico, a tarefa consiste em idear uma concepção bidimensional da justiça que possa integrar tanto as reivindicações defendíveis de igualdade social como as do reconhecimento da diferença. Na prática, a tarefa consiste em idear uma orientação política programática que possa integrar o melhor da política de redistribuição com o melhor da política de reconhecimento (FRASER; HONNETH, 2006, p. 19).

Segundo Honneth, mesmo as injustiças de redistribuição, da ordem da economia, deveriam ser entendidas como demandas não atendidas de reconhecimento, como demonstrações sociais de desrespeito.

A motivação para o comportamento de protesto social por parte das camadas mais pobres não se baseia na orientação de princípios da moral formulados positivamente, mas na experiência da violação de ideias de justiça dadas intuitivamente; e o núcleo normativo dessas ideias de justiça consiste uma e outra vez em expectativas relacionadas com o respeito até a própria dignidade, a honra e a integridade. Ora, se se generalizam esses resultados mais além de seus respectivos contextos de investigação, se apresenta a conclusão de ver na aquisição do reconhecimento social a condição normativa de toda ação comunicativa (HONNETH, 2011, p. 136).

Há, no multiculturalismo ligado ao capitalismo global, a ilusão de um pluralismo sem antagonismo: 
[...] ilusão baseada no esquecimento de que identidades, sejam políticas ou psicológicas, sempre são construídas no interior de relações assimétricas de poder, sendo por isso expressões de estratégias de defesa ou de dominação (SAFATLE, 2015, p. 349).

O multiculturalismo tenta resolver isso através de uma "politização das diferenças culturais", construindo uma política da tolerância. Como diz Safatle, esse equacionamento das diferenças parte da questão "até onde podemos suportar as diferenças?” (SAFATLE, 2015). Com isso, porém, permanecemos no círculo das diferenças isoladas, sem que se possa construir lógicas mais ampliadas que não atolem nas diferenças ou patolem nas políticas meramente compensatórias para alcançar uma política que integre reconhecimento e redistribuição, ou seja, demandas culturais e econômicas, como propunha Fraser em sua polêmica com Honneth (FRASER; HONNETH, 2006).

Nesse sentido, o multiculturalismo é um complemento do neoliberalismo, para o qual só há o indivíduo concorrendo com os demais. Safatle propõe que se pense a política fora dessa conjunção de economia e cultura:

[...] a política é, acima de tudo, uma força de des-diferenciação capaz de abrir aos sujeitos um campo produtivo de indeterminação. Sujeitos políticos não são portadores de demandas individuais representativas de certos grupos particulares, estamentos e classes (SAFATLE, 2015, p. 354).

Portanto, o combate aos biopoderes deve investir na direção da indeterminação e numa mudança do circuito dos afetos a fim de criar movimentos/acontecimentos que não se ancorem nas conquistas individuais. Nessa direção, devemos pensar a comunicação a partir das cenas de conflito honnethiano e não num parlamento em que se busca consensos habermasianos.

Em Laclau, o movimento pela construção do povo só se pode dar a partir de uma falta, uma brecha que emerge na aparente continuidade do social. Aí se projeta uma plenitude ausente. "A construção do povo seria a tentativa de dar um nome a essa plenitude ausente" (LACLAU, 
2013, p. 140). A falta seria ligada a uma demanda não atendida pelos poderes em vigência. Aí se coloca uma fratura entre demandas não atendidas e os poderes que não as atenderam. A demanda não precisa ser algo como o preço do trigo, pode ser mais abstrata, como o atendimento aos direitos do cidadão, da mulher, do homossexual, de trans. Ou seja, em Laclau, o movimento não pode ser puramente anarquista, devendo costurar as diferenças através de uma lógica equivalencial que se contraponha aos discursos hegemônicos.

A política tem, portanto, de ser acontecimental no sentido de que tem de desfazer os modos de ordenamento do visível, do legível e do representável, e isso não é da ordem do desenvolvimento somente individual. Como dizíamos com Badiou, é preciso desfazer a lei nesses modos de ordenamento, de nomeação das coisas, dos elementos que fazem parte dos conjuntos representáveis, visíveis, correspondentes a descrições entendidas como claras e distintas, reconhecíveis. O acontecimento altera os estados de coisas dos mundos, introduzindo a possibilidade de novos processos de verdades desde que haja sujeitos fiéis ao acontecimento. Badiou define desejo como a busca de algo para além da normalidade da lei, desejo como "singularidade". É nesse sentido que falamos em política acontecimental, que pode iniciar um novo processo comunicacional.

\section{Ocupando a praça, inventando o público}

Consideremos o exemplo dos movimentos Occupy, como o de Wall Street (OWS), que tomaram as cidades norte-americanas em 2011 e 2012. Eles começam com reuniões de algumas poucas dezenas de ativistas e se ampliam até reunir milhares. A ideia era promover um ativismo horizontal que não se subordinasse às estratégias viciadas de movimentos tradicionais ligados a sindicatos e partidos; o movimento pretendia ocupar uma praça próxima à bolsa de valores e chamar para o local ativistas horizontais. Era preciso ter propostas iniciais para contaminar outras pessoas e ampliar o movimento. A ideia inicial para a convocação veio de David Graeber: o um por cento mais rico da população não 
apenas concentrava a riqueza do país, mas transformava essa riqueza em poder político (GRAEBER, 2015, p. 57). Como disse Joseph Stiglitz,

[...] praticamente todos os senadores americanos e a maioria dos deputados, quando chegam à Câmara, fazem parte do um por cento mais rico, são mantidos no poder pelo dinheiro do um por cento mais rico e sabem que, se servirem bem a esse um por cento, serão recompensados quando deixarem o cargo (STIGLITZ in GRAEBER, 2015, p. 57).

Daí denominar a ação do OWS de "movimento dos 99\%”. Os ativistas queriam partir do que já tinha sido realizado nas praças de Cairo, Atenas, Barcelona e Madri, “onde milhares de cidadãos comuns, a maioria sem nenhum preparo em termos de mobilização política, estavam dispostos a ocupar praças públicas em protesto contra toda a classe política de seu país" (GRAEBER, 2015, p. 58). O Occupy decidiu adotar a tática não violenta de Gandhi, embora ela tivesse fracassado em movimentos anteriores - como no caso dos defensores de florestas nos anos 1990, que foram torturados pela polícia sem que a mídia desse atenção; além disso, "os tribunais locais consideraram aceitável a tática de aplicar spray de pimenta nos olhos. Sem cobertura da imprensa nem recurso legal, as contradições que as táticas de Gandhi deveriam desvelar simplesmente se perderam" (GRAEBER, 2015, p. 76). No caso do Occupy, tais táticas funcionaram, pois as mídias deram atenção ao movimento nas pegadas da repercussão internacional. Além dessa mudança de atenção por parte das mídias, Graeber atribui o espalhamento de notícias e vídeos às atividades nas redes sociais, embora, diz o autor, isso não explique por que o movimento se espalhou tão rapidamente por todo o país (GRAEBER, 2015 , p. 80). Aqui conta algo como um sentimento de "vergonha, desonra e forte indignação por ouvir que se é um perdedor num jogo que ninguém o obrigou a jogar" (GRAEBER, 2015, p. 81). Graeber conta a história de uma moça que:

Embora fosse de origem modesta, tinha conseguido ingressar em um curso de doutorado em literatura renascentista em uma faculdade da Ivy League. O resultado? Tinha uma dívida de 80 mil dólares e nenhuma perspectiva imediata a não ser trabalhar como assistente, o que não dava 
nem para cobrir o aluguel, muito menos as parcelas do financiamento (GRAEBER, 2015, p. 82).

Terá o Occupy sido um acontecimento ao trazer para a praça um conjunto de pessoas e grupos muito diferentes que unificaram sua luta contra o neoliberalismo através de uma lógica equivalencial (LACLAU, 2015)? Isso é uma discussão difícil de estabelecer, mas podemos considerar que esse movimento anarquista coloca em questão algo importante nesses tempos neoliberais: democracia não é isso que se define pelo voto da maioria, mas "o processo de deliberação coletiva sob o princípio da participação plena e igualitária” (GRAEBER, 2015, p. 187). Nesse sentido, as pessoas reunidas na praça para deliberar constituem um acontecimento para a democracia, pois fazem a experiência de um comum. Diante disso, os poderes constituídos reagem fortemente. A experiência da democracia não surge, portanto, de dentro do sistema político instituído, mas vem do mundo da vida, dessas experiências que suspendem os discursos hegemônicos (o neoliberal, o de que não há outra forma de vida senão sob o capitalismo etc.). Não é de idealização que estamos falando. A questão é: como discursos pela democracia radical podem ser constituídos fora dos circuitos corrompidos do sistema tradicional? Não basta constituir coalizões equivalenciais que reúnam diferenças para criar um movimento contra-hegemônico, porque para governar seria preciso entrar numa máquina de governamentalidade já corrompida. Por isso, o sentido mais básico de anarquismo - a saber, um governo "sem governantes" - é que realmente importa aqui e não a idealização romântica de um comunitarismo sem líderes. Esse "sem governo" evoca uma certa sensibilidade política que propõe um conjunto de relações que não apele à força e à violência para ser imposto. Como diz Graeber, "nunca se alcançarão os fins a menos que os meios sejam, eles próprios, um modelo do mundo que se quer criar" (GRAEBER, 2015). Não podemos negociar com bandidos se queremos mudar os modos de sociabilidade e de governamentalidade. 


\section{Corpos em aliança e a política das ruas}

Butler, em um artigo durante as manifestações pós-2010, como por exemplo na praça Tahir, fala de todas essas experiências de estar junto:

[...] aquelas no inverno de 2011 contra regimes tirânicos no norte da África e no Oriente Médio, mas também contra a crescente precarização dos trabalhadores na Europa e no hemisfério sul, as lutas pela educação pública por todos os EUA e Europa, e aquelas lutas para tornar a rua mais segura para as mulheres, minorias de gênero e sexuais, incluindo pessoas trans, cuja visibilidade pública é com bastante frequência punida com violência legal e ilegal (BUTLER, 2011).

Para a autora, os corpos congregaram em movimento, em conversa, reivindicando um espaço público. Os corpos não entraram em um espaço público já dado de antemão, já institucionalizado, pois o caráter público do espaço já faz parte da disputa. Esse público que o movimento constrói na praça é performativo na medida em que o constitui ao nomeá-lo em ato. A polícia, quando agride os manifestantes, está recusando essa perspectiva dos movimentos. Ela sustenta um público neoliberal que, a rigor, não é público, mas espaço individualista. A política não deve ser pensada como atividade exclusiva da esfera pública, diz Butler, pois "ela atravessa essa linha sempre e novamente, trazendo atenção para o modo pelo qual a política já está em casa, na rua ou na vizinhança, ou mesmo naqueles espaços virtuais que estão desvinculados da arquitetura da praça pública" (BUTLER, 2011).

O que significa, então, se reunir em uma multidão, contestando a distinção entre público e privado? Essa reunião, esse reunir de gentes, de singularidades que não respondem a uma soberania unívoca, é a reivindicação do público, de modo a se produzir, no próprio fazer, o público desse reunir, recusando os regimes de instauração de uma visibilidade, de uma interação e de uma governamentalidade fixados anteriormente e sustentados pelo poder de polícia. Comunicação acontecimental é justamente o processo desse reunir reivindicando performativamente o público. O reunir é a própria reconfiguração acontecimental 
(intensividade) do ambiente, do material que constitui os entornos e as bases do encontro (a rua, a praça). Não há ação coletiva sem esses materiais. Quando caminhões se tornam plataformas para a fala dos integrantes da multidão ou quando os microfones humanos repetem os discursos para que sejam ouvidos por todos, trata-se de materializar esse reunir, esse efeito dos corpos em junção. A ação depende não somente da multidão, mas dos suportes materiais e das intervenções realizadas a cada momento. Ao se efetivarem as próprias ações da multidão, dá-se uma luta em ato sobre o que realmente constitui e sobre o que será o espaço público (enquanto isso se faz no sendo), mas também sobre "os modos básicos pelos quais somos, como corpos, suportados no mundo uma luta contra privação de direitos e abandono", contra a precarização da vida (BUTLER, 2011).

O espaço público não é somente o suporte material dado pelas ruas e praças, mas surge, no encontro dos corpos, como espaço de visibilidade e de interação. Butler fala de um "espaço de aparecer" que surge entre os participantes - em presença, como diriam os semioticistas - quando a aliança se faz, na própria medida em que a aliança se vai fazendo, no gerúndio da ação - comunicação em presença. Ao aparecer para o outro, nesse gerúndio do encontrar dos corpos em praça, os corpos não estão aí como vidas nuas, mas como corpos políticos num espaço de ação plural. A ação cria a locação, pois ela não parte de um local que suporta previamente a ação: esse local criado em ato é parte da disputa. Nesse sentido, o em público é performativo. No ato de enunciá-lo, de materializá-lo, na própria interação, os corpos criam-no. O discurso surge na medida em que os corpos se reúnem e agem.

Para repensar o espaço de aparição (ou de visibilidade) a fim de entender o poder e o efeito das demonstrações públicas de nosso tempo, precisaremos entender as dimensões corporais da ação, o que o corpo requer e o que o corpo pode fazer, especialmente quando devemos pensar sobre os corpos juntos, o que os mantém juntos, suas condições de persistência e de poder (BUTLER, 2011). 
Essas alianças podem, como diz Butler, adquirir o poder performativo, num momento anarquista, contra regimes tirânicos (caso do Egito, por exemplo, em 2011), contra as dívidas dos estudantes e dos trabalhadores nos EUA, contra a precarização da vida, na busca de melhor habitação, de passe livre nos transportes do Estado, de segurança para as mulheres nas ruas ou de respeito à escolha sexual das minorias (BUTLER, 2011). É um intervalo em que se questiona o poder, o governo, se faz reivindicações que ainda não estão codificadas em lei. O que nos interessa aqui é essa dimensão acontecimental do atuar juntos, reunidos, que "abre tempo e espaço fora e contra a temporalidade e a arquitetura estabelecida do regime" e que pode reconfigurar o que é o público.

Para a política ter lugar, o corpo deve aparecer. Um corpo aparece para os demais, havendo um espaço entre os corpos que permite essas aparições. Isso não cria apenas uma visualidade, mas uma audiência, pois as vozes circulam.

O que somos, corporalmente, já é um modo de ser "para” o outro, aparecendo de modos que não podemos ver, sendo um corpo para o outro de um modo que não posso ser para mim mesmo, e assim, despossuídos, em perspectiva, por nossa própria sociabilidade (BUTLER, 2011).

Devo aparecer para outros de modos "para os quais não posso dar conta (give an account) e desse modo meu corpo estabelece uma perspectiva que não posso habitar". O corpo estabelece não apenas a minha própria perspectiva, diz Butler, mas ele desloca essa perspectiva e torna esse deslocamento uma necessidade.

Isso ocorre mais claramente quando pensamos em corpos que agem juntos. Nenhum corpo estabelece o espaço do aparecer (appearance), mas essa ação, esse exercício performativo ocorre apenas "entre" dois corpos, em um espaço que constitui a lacuna entre meu corpo e o do outro. Dessa forma, meu corpo, quando ele atua politicamente, não atua sozinho. De fato, a ação emergiu a partir do "entre" (BUTLER, 2011). 


\section{Discurso e insurreição}

Com o acontecimento, as diferenças podem emergir em reunião na praça e fazer com que se crie uma lógica equivalencial (termo de LACLAU, 1996). Após o acontecimento, porém, cria-se um novo campo antagonista em que existem vários tipos de sujeitos em relação ao acontecimento: aqueles fiéis ao acontecimento, que se lançam, a partir dele, a construir um mundo na política, na arte, na ciência ou no amor, mas há também sujeitos reativos, que recusam o acontecimento. Esses sujeitos reativos em geral se ligam ao poder de polícia. Nesse novo campo, vários discursos disputam os sentidos do acontecimento, fazendo com que a intensidade máxima da erupção acontecimental vá caindo na extensividade discursiva, de modo que aquele primeiro momento de afetividade máxima ceda espaço à legibilidade do acontecimento, que surge aos poucos, na medida em que os sentidos vão sendo construídos pelos discursos em disputa. Para que essas disputas se deem na direção da democracia radical, é preciso que as esquerdas expandam "as cadeias de equivalência entre as diferentes lutas contra a opressão” (LACLAU; MOUFFE, 2015, p. 264).

Para isso se dar, é preciso entender a teoria do discurso não como um instrumento só para leitura de textos, mas como crítica naquele sentido de que falam Butler e Foucault, ou seja, como cinto de utilidades para a leitura de práticas e dispositivos, incluindo as redes que constituem esses dispositivos: legislação, decretos, leis, instituições, práticas, regulamentos etc. A teoria do discurso deve atuar em ato na reunião das diferenças que se colocam a pensar, em conjunto, novos mundos. Nesse sentido, ele não é teoria, mas práxis.

Chegamos, portanto, a algumas conclusões que são necessárias para o entendimento de uma teoria da comunicação e uma teoria do discurso que não seja somente exame de textos verbais, visuais ou verbivisuais, mas também de práticas ligadas aos modos de funcionamento das biopotências em sua luta contra os biopoderes. Essa teoria se ancora em um Foucault que leu Butler e Laclau. Senão vejamos: em Foucault, tratava-se, por exemplo, na história da sexualidade, de entender como se dá 
para os indivíduos a experiência da sexualidade que os leva a "reconhecer-se como sujeitos de uma sexualidade” (FOUCAULT, 2009, p. 10). Experiência para ele significa "a correlação, em uma cultura, entre campos de saber, tipos de normatividade e formas de subjetividade”. Assim, fazer uma história da sexualidade não é entender suas formas sucessivas no tempo como efeitos de formas de repressão, pois isso colocaria "fora do campo histórico o desejo e o sujeito do desejo” (FOUCAULT, 2009).

Em resumo, a forma geral da interdição não pode dar conta do que há de histórico na sexualidade, da mesma forma que, em Butler, o sujeito não pode ser entendido apenas se considerarmos sua subordinação às normas, mas é sempre preciso pensar o espaço da agência, da criatividade que permite que ele se des-subordine e abra campo para os acontecimentos. Para dar conta dessa história, é preciso enfrentar três eixos, nos diz Foucault:
A. a formação dos saberes ligados à sexualidade;
B. os sistemas de poder que regulam sua prática;
C. as formas pelas quais os indivíduos se reconhecem como sujeitos dessa sexualidade (FOUCAULT, 2009).

Aqui entra a teoria do discurso como análise das práticas ligadas ao dispositivo da sexualidade, ou seja, a rede constituída por regulamentos, leis, normas, decretos, documentos, instituições, formação profissional ligada a esse campo etc. Com ela é possível, em particular, examinar como se dá a formação de saberes, "escapando ao dilema entre ciência e ideologia” (FOUCAULT, 2009, p. 11); mas, paralelamente, é preciso empreender a análise das relações de poder e suas tecnologias "escapando à alternativa entre um poder concebido como dominação ou denunciado como simulacro" (FOUCAULT, 2009, p. 11). Em relação ao último item, do reconhecimento do indivíduo como sujeito do desejo, Foucault propõe empreender uma genealogia; trata-se de

[...] analisar as práticas pelas quais os indivíduos foram levados a prestar atenção a eles próprios, a se decifrar, a se reconhecer e se confessar como sujeitos de desejo, estabelecendo de si para consigo uma certa relação que lhes permite descobrir, no desejo, a verdade de seu ser, seja ele natural ou 
decaído. [...] Em resumo, para compreender de que maneira o indivíduo moderno podia fazer a experiência dele mesmo enquanto sujeito de uma "sexualidade", seria indispensável distinguir previamente a maneira pela qual, durante séculos, o homem ocidental fora levado a se reconhecer como sujeito de desejo (FOUCAULT, 2009, p. 12).

Com isso, vemos que a política é essa intervenção dos corpos batalhando nessa perspectiva performativa na busca das linhas de fuga dos discursos hegemônicos. Para haver política é preciso haver acontecimento e, para isso, corpos anarquistas, nem que seja no momento da intensidade máxima do acontecimento. Podemos pensar que o falante/ agente, ao entrar na cultura, vai sendo afetivamente marcado em seu corpo, vai fazendo suas escolhas e, na mesma medida, sendo escolhido pelos discursos e pelas constelações afetivas neles investidos. Há, portanto, uma tendência de cristalização de afetos e discursos nos corpos a partir de disciplinas, controles e pedagogias ligadas aos dispositivos sistêmicos. O corpo é, desse modo, marcado pelas palavras, pelos discursos. Vários discursos tentam dar conta do que ocorre num campo a partir de posições diversas de sujeitos, com seus desejos, interesses e demandas. Essa luta de posições não envolve apenas argumentos, mas práticas enraizadas em valores encarnados em corpos afetados, ou seja, os valores dominantes encarnam em corpos que não agem apenas cognitivamente, mas também afetivamente. Isso vale para as disputas discursivas nos mais variados temas, como o da sustentabilidade, do empreendedorismo e do populismo. Esses afetos estão enraizados, incorporados, encarnados desde que o bebê mamou no peito da mãe ou mesmo desde que estava em sua barriga, ouvindo e sentindo o mundo ao redor. O aprendizado da linguagem é corporal e não há um sujeito prediscursivo. O corpo suporta vários sujeitos e eles respondem a discursos e práticas. O sujeito é efeito de um discurso: de um lado, como em Foucault, o sujeito é assujeitado a discursos que o constituíram; de outro, ele é capaz de agência, como em Butler, podendo realizar subversão. Esse assujeitamento foi marcado no corpo por uma linguagem negativadora, de cuja negativação emergiram pulsões. 
A semiótica das paixões fala num sujeito protensivo, o que implica imaginar um sujeito pré-consciência, mergulhado no magma do Lebenswelt, do mundo da vida com suas formas atemáticas, semânticas e pragmáticas, espécie de inconsciente fenomenológico em que o dasein bebe para produzir seus discursos, que, aliás, como diria Greimas, tem seus perfumes. O sujeito protensivo não está apenas mergulhado nesses perfumes acontecimentais do mundo da vida, pois há sombras nesse mundo. É um mundo carregado de afetos, pois as formas de palavrear e de sentir os estados de coisas, os estados subjetivos e sociais não são desafetadas. O mundo da vida (Lebenswelt) é um estofo de linguagens carregado de afetos. Essa experiência que brota através do cipoal do mundo da vida não é gerada monologicamente pela consciência individual, mas vivência corporal comunicativa trazida na medida em que o dasein entra na linguagem, nos coletivos, sendo a família o primeiro deles. É na relação com o outro, desde cedo, desde que a mãe lhe dá o peito, que o bebê-dasein é sugado para dentro da linguagem, na mesma medida em que suga o peito ao se alimentar, aprendendo que alimento é mãe e é afeto. Alimentar-se é, desde cedo, afetar-se pelo e do outro; ou, como diz Lacan, envolve prazer de boca, o que nos tira da hierarquia de necessidades de Maslow.

Há dois níveis nessas leituras discursivas:

1. foucaultiano-butleriano, que está em localizar a série histórica dos enunciados que constituíram a força do dispositivo a ser estudado (por exemplo, o dispositivo psiquiátrico, o neoliberalismo etc);

2. análise dos textos (inclusive práticas) envolvidos no funcionamento do dispositivo em questão em cada caso.

É preciso lembrar que a afetividade não opera apenas através dos discursos, mas também dos acontecimentos. Além disso, o circuito dos afetos está intimamente ligado às disputas pelos sentidos dos acontecimentos, quando os discursos e os dispositivos entram em disputa a fim de iluminar os primeiros. Os discursos estão afetados pelos afetos e atingem os corpos - ou seja, incorporam-se, encarnam. 


\section{Referências}

BADIOU, A. Philosophy for militants. Londres: Verso, 2012.

Lógicas de los mundos. Buenos Aires: Manantial, 2008.

BOLTANSKI, L.; CHIAPELO, E. O novo espírito do capitalismo. São Paulo: Martins Fontes, 2009.

BUTLER, J. Bodies in alliance and the politics of the street. 2011. Disponível em: http:// eipcp.net/transversal/1011/butler/en.

.; SALIH, S. The Judith Butler Reader. Oxford: Blackwell, 2004.

DARDOT, P.; LAVAL, C. A nova razão do mundo. Ensaio sobre a sociedade neoliberal. São Paulo: Boitempo, 2016.

DUNKER, C. I. L. Mal-estar, sofrimento e sintoma. São Paulo: Boitempo, 2015.

FOUCAUlT, M. História da sexualidade. v. 2. O uso dos prazeres. São Paulo: Graal, 2009.

Nascimento da biopolítica. São Paulo: Martins Fontes, 2008.

FRASER, N.; HONNETH, A. Redistribuición o reconocimiento? Madri: Morata/Paideia, 2006.

FREIRE FILHO, J. Ser feliz hoje. Rio de Janeiro: Globo Universidade: FGV, 2010.

GRAEBER, D. Um projeto de democracia. São Paulo: Paz \& Terra, 2015.

HONNETH, A. La sociedade del desprecio. Madri: Trotta, 2011.

Luta por reconhecimento. São Paulo: 34, 2003.

LACLAU, E. A razão populista. São Paulo: Três Estrelas, 2013.

.; MOUFFE, C. Hegemonia e estratégia socialista. São Paulo: Intermeios, 2015.

PRADO, J. L. A. A política do performativo em Butler. In: GREINER, C. (Org.). Leituras de Judith Butler. São Paulo: Annablume, 2016a. p. 15-35.

PRADO, J. L. A. Comunicação como epistemologia do sul: do reconhecimento à emergência do acontecimento. Matrizes (on-line), v. 9, p. 109-125, 2015.

Comunicação e reinvenção acontecimental da política. In: JESUS, E.; TRIN-

DADE, E.; JANOTTI JR., J.; ROXO, M. (Orgs.). Reinvenção comunicacional da política. Salvador: EdUFBA, 2016b. p. 15-30.

PRADO, J. L. A. Da convocação da alma gêmea ao acontecimento amoroso. In: PINHEIRO, A; SALLES, C. (Orgs.). Jornalismo expandido: práticas, sujeitos e relatos entrelaçados. São Paulo: Intermeios, 2016c. p. 127-145.

PRADO, J. L. A. Política do acontecimento. FAMECOS (on-line), v. 20, p. 495-520, 2013.

.; PRATES, V. O afastamento de Dilma Roussef: afetos e discursos em disputa na política. In: ENCONTRO ANUAL DA COMPÓS, 26., 2017, São Paulo. Anais... São Paulo: Faculdade Cásper Líbero, 2017.

RANCIÈRE, J. O desentendimento. São Paulo: 34,1996.

SAFATLE, V. Cinismo e falência da crítica. São Paulo: Boitempo, 2008.

O circuito dos afetos. São Paulo: Cosac \& Naify, 2015.

VIVEIROS DE CASTRO, E. A inconstância da alma selvagem e outros ensaios. São Paulo: Cosac \& Naify, 2002. 


\section{Sobre o autor}

É professor doutor no Programa de Estudos Pós-graduados em Comunicação e Semiótica da PUC-SP e editor da revista Galáxia. Autor de Habermas com Lacan e Convocações biopolíticas dos dispositivos comunicacionais. Coordenador do Grupo de Pesquisas em Mídia e Discurso - Um dia sete dias.

Data de submissão: 06/01/2017

Data de aceite: 30/01/2017 